\title{
Evaluation of the Sensitivity of the Weather Research and Forecasting Model to Parameterization Schemes for Regional Climates of Europe over the Period 1990-95
}

\author{
P. A. MOONEY \\ Department of Physics, University of Oxford, Oxford, United Kingdom, and ICARUS, Department of Geography, \\ National University of Ireland Maynooth, Kildare, Ireland \\ F. J. MulLiGAN \\ Department of Experimental Physics, National University of Ireland Maynooth, Kildare, Ireland \\ R. FEALY \\ Department of Geography, National University of Ireland Maynooth, Kildare, Ireland
}

(Manuscript received 17 November 2011, in final form 23 July 2012)

\begin{abstract}
The Weather Research and Forecasting model (WRF) is used to downscale interim ECMWF Re-Analysis (ERA-Interim) data for the climate over Europe for the period 1990-95 with grid spacing of $0.44^{\circ}$ for 12 combinations of physical parameterizations. Two longwave radiation schemes, two land surface models (LSMs), two microphysics schemes, and two planetary boundary layer (PBL) schemes have been investigated while the remaining physics schemes were unchanged. WRF simulations are compared with Ensemble-Based Predictions of Climate Changes and their Impacts (ENSEMBLES) observations gridded dataset (E-OBS) for surface air temperatures (T2), precipitation, and mean sea level pressure (MSLP) in eight subregions within the model domain to assess the performance of the different parameterizations on widely varying regional climates. This work shows that T2 is modeled well by WRF with high correlation coefficients $(0.8<R<0.95)$ and biases less than $4^{\circ} \mathrm{C}$. T2 shows greatest sensitivity to land surface models, some sensitivity to longwave radiation schemes, and less sensitivity to microphysics and PBL schemes. Precipitation is not well modeled by WRF with low correlation coefficients $(0.1<R<0.3)$ and high root-mean-square differences (RMSDs; $8-9 \mathrm{~mm} \mathrm{day}^{-1}$ ). Precipitation shows sensitivity to LSMs in summer. No significant bias has been observed in the MSLP modeled by WRF. Correlation coefficients are typically in the range $0.7<R<0.8$ while RMSDs are in the range $6-10 \mathrm{hPa}$. MSLP output is sensitive to longwave radiation scheme in summer but is relatively insensitive to either microphysics or the choice of LSM. The optimum combination of parameterizations for all three state variables examined is strongly dependent on subregion and demonstrates the need to carefully select parameterization combinations when attempting to use WRF as a regional climate model.
\end{abstract}

\section{Introduction}

The Advanced Research Weather Research and Forecasting model (ARW-WRF, hereafter WRF) developed at the U.S. National Center for Atmospheric Research (NCAR) in Boulder is a nonhydrostatic mesoscale numerical weather prediction system originally designed for weather forecasting that is freely available

\footnotetext{
Corresponding author address: P. A. Mooney, ICARUS, Department of Geography, National University of Ireland Maynooth, Kildare, Ireland.

E-mail: priscilla.a.mooney@nuim.ie
}

to the atmospheric community for research. It is increasingly in use throughout the world as a regional climate model (RCM) for dynamical downscaling of global models for two separate purposes. The first of these is its use with different global climate models (GCMs) in an attempt to determine long-term trends in the climate of a given region (e.g., Caldwell et al. 2009; Zhang et al. 2009; Salathé et al. 2010). An alternative and sometimes complementary application of WRF is to increase the resolution beyond that available from the GCM (or reanalysis data) for a particular geographic region and often with a particular state variable or local phenomenon in mind (e.g., Borge et al. 2008; Flaounas 
et al. 2010; Evans and McCabe 2010; Mercader et al. 2010; Prabha et al. 2011).

Salathé et al. (2010) compared two 100-yr regional climate simulations for the State of Washington using WRF. One simulation was forced by the NCAR Community Climate System Model version 3 (CCSM3) and the second was driven by the Max Plank Institute Hamburg ECHAM5 global model. These two mesoscale simulations produced regional changes that substantially altered the temperature and precipitation trends over the region relative to global model result or statistical downscaling. Caldwell et al. (2009) performed a 40-yr WRF-based dynamical downscaling simulation centered on California forced with CCSM3. They reported a precipitation bias (overestimated rainfall along windward slopes) that was caused by processes internal to WRF, and a coastal (warm) temperature bias due to an SST bias inherited from CCSM3. Evans and McCabe (2010) used a WRF regional climate model simulation over Australia's Murray-Darling basin, which was initialized by NCEP-NCAR reanalysis data. They evaluated the simulated climate against gridded precipitation and temperature observations at daily, monthly, interannual, and multiannual time scales, and found that WRF successfully reproduced daily statistics compared with observations, and it improved monthly and interannual statistics relative to NCEP-NCAR reanalysis.

One of the reasons for the popularity of WRF as an RCM is that it includes a wide range of physical parameterizations, and it can be initialized either by data from a GCM or by reanalysis data. This makes it ideal for the study of phenomena that require high resolution (e.g., precipitation distribution in an orographically complex region). Typically, RCM applications of WRF use only one combination (or at best a small number) of the available parameterization schemes because of the high computational cost associated with running all possible combinations. The WRF parameterizations are generally held constant in these investigations, which represent a test of the different GCMs. The difficulty with this type of investigation is that a given GCM might perform better (or worse) with a particular parameterization, and the investigator is often faced with the difficulty of disentangling the error contribution of WRF from that of the GCM. In both of these instances considerable energy is expended in determining the optimum set of parameterizations for the particular purpose.

Borge et al. (2008) studied the sensitivity of WRF for air quality applications over the Iberian Peninsula for two 1-week periods in the winter and summer of 2005. They found that a particular scheme or option rarely produced the best results for all the statistical parameters and/or geographical locations examined. As a result, they provided the optimum configuration for the model based on aggregated performance. Flaounas et al. (2010) examined the sensitivity of WRF to convection and planetary boundary layer (PBL) parameterization in a study of the 2006 West African monsoon (WAM). They found that PBL schemes had the strongest effect on the vertical distribution of temperature, humidity, and rainfall amount, whereas dynamic and precipitation variability were particularly sensitive to convection parameterization schemes. Bukovsky and Karoly (2009) examined the effects of different land surface models and cumulus schemes on precipitation over North America modeled by WRF for the months of May, June, July, and August over the period 1991-95. Their study showed that the precipitation was sensitive to the choice of land surface model and cumulus scheme. Bukovsky and Karoly (2009) emphasized the importance of testing WRF output for sensitivity to parameterizations for regional climate modeling applications.

Typically, the performance of a climate model is evaluated based on its ability to simulate the present climate. Ideally, the model should capture annual and interannual variability and the spatial patterns of temperature, precipitation and mean sea level pressure. Reichler and Kim (2008) define a Model Performance Index (MPI) for GCMs based on a standardized average mean squared error and combine the performance of multiple climate variables in a single number. In the evaluation of regional climate models there appears to be no general set of performance metrics. In the Fourth Assessment Report (AR4) of the Intergovernmental Panel on Climate Change (IPCC; Solomon et al. 2007), the skill of regional climate models in simulating the present climate is discussed in terms of biases and interannual variability. This approach was also adopted by Jacob et al. (2007) for evaluating the performance of the regional climate models used in the Prediction of Regional Scenarios and Uncertainties for Defining European Climate Change Risks and Effects (PRUDENCE) project. Their evaluation focused on the long-term mean climate and the interannual variability of near surface temperature and precipitation over land during the winter and summer seasons.

Perkins et al. (2007) employed probability density functions (PDFs) in their evaluation of coupled climate models over 12 regions in Australia for the daily simulation of precipitation, minimum temperature, and maximum temperature. They point out that simulating a whole PDF is a far harder test of a model than simulating the mean and one standard deviation alone. They used a simple metric that evaluates the area of overlap of the PDFs of the observed parameter and the modeled version. A model that simulates the observed parameter 
perfectly would score one, while a model that simulates the observed PDF poorly would have a score close to zero.

In this study, we examine WRF as an RCM for a European domain [World Climate Research Programme (WCRP) Coordinated Regional Climate Downscaling Experiment (CORDEX) region 4; http://wcrp.ipsl.jussieu. fr/cordex/domains.html] over the period 1990-95 with a view to identifying the optimum choice of parameterizations for climate modeling studies with WRF over Europe. We employ reanalysis data to provide the initial conditions and the lateral boundary information at 6-hourly intervals, thereby avoiding the uncertainty associated with the use of a GCM. The most advanced reanalysis data available for this purpose is the interim European Centre for Medium-Range Weather Forecasts (ECMWF) Re-Analysis (ERA-Interim), where recent studies have shown that it provides the best representation of certain aspects of the climate system (Mooney et al. 2011; Troy and Wood 2009; Screen and Simmonds 2010). We use a grid spacing of $0.44^{\circ} \times 0.44^{\circ}$ to economize on the computational effort required over the relatively large domain.

Our assessment of different WRF parameterizations involves a detailed examination of three state variables over eight Rockel subregions (Christensen and Christensen 2007) representing very different regional climates within the domain. The WRF output of surface air temperature at $2 \mathrm{~m}$ (T2), precipitation (PR), and mean sea level pressure (MSLP) are assessed by comparison with the Ensemble-Based Predictions of Climate Changes and their Impacts (ENSEMBLES) observations gridded dataset (E-OBS) observational dataset (Haylock et al. 2008; van den Besselaar et al. 2011). Unlike previous studies (Bukovsky and Karoly 2009; Jin et al. 2010; Flaounas et al. 2010), we investigate the sensitivity of a greater range of parameterization schemes over a longer continuous period of time. All three state variables are assessed for bias in spatial distribution, seasonal (summer/winter) patterns, and monthly averages, for mismatch in the temporal component through correlation coefficients, and in the extent of variability through standard deviation, PDF, and root-mean-square difference (RMSD).

\section{Experimental setup}

\section{a. Model details for initialization and domain}

The climate over the CORDEX European domain shown in Fig. 1 was simulated using the fully compressible nonhydrostatic WRF (ARW-WRF version 3.1; Skamarock et al. 2008) at a horizontal grid spacing of $0.44^{\circ} \times 0.44^{\circ}$ over the period $1990-95$. We chose 40

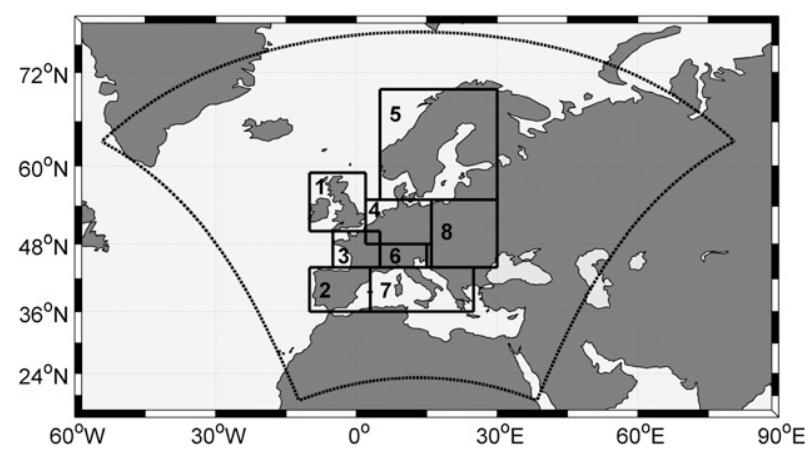

FIG. 1. Map showing the CORDEX European domain modeled by WRF (dashed line) and the eight European subregions (Christensen and Christensen 2007) (solid lines). The subregions are 1: British Isles (BI), 2: Iberian Peninsula (IP), 3: France (FR), 4: mid-Europe (ME), 5: Scandinavia (SC), 6: Alps (AL), 7: Mediterranean) (MD), and 8: eastern Europe (EE).

full eta levels in the vertical as follows: 1.000, 0.993, $0.983,0.970,0.954,0.934,0.909,0.880,0.843,0.805,0.768$, $0.731,0.664,0.602,0.546,0.493,0.444,0.400,0.359,0.321$, $0.286,0.254,0.225,0.199,0.174,0.152,0.132,0.114,0.098$ $0.083,0.070,0.058,0.047,0.038,0.029,0.022,0.015,0.010$ 0.005 , and 0.000 . ERA-Interim was used to provide initial conditions, lateral boundary values, and sea surface temperatures (SSTs) at 6-hourly intervals for each simulation. The period 1990-95 was chosen for this study based on availability of ERA-Interim data and limited computational resources due to the relatively large model domain. A 1-yr spinup period was employed for all the results presented below. We discuss the effect of this spinup period on our results in section $3 \mathrm{a}$. We consider that for a preliminary study of WRF as a regional climate model, a 6-yr period will enable us to determine its sensitivity to different parameterization schemes with a view to longer-term simulations.

\section{b. Parameterization schemes-Configurations}

Parameterization schemes in WRF can be broadly categorized into 1) microphysics, 2) longwave radiation, 3) shortwave radiation, 4) land surface model, 5) convective schemes, and 6) planetary boundary layer. Within each of these categories there exist numerous parameterization schemes, some of which are more applicable to climate modeling while others are better suited for weather forecasting. The sensitivity of WRF model to the parameterization schemes illustrated in Table 1 is assessed by examining its ability to reproduce spatial and temporal patterns of the mean European climate.

Land surface models (LSMs) evaluated were the Noah (Ek and Mahrt 1991) and Rapid Update Cycle (RUC) (Smirnova et al. 1997, 2000) schemes. Both of these models have soil temperature and moisture, snow 
TABLE 1. Physical parameterizations schemes used in each of the WRF simulations.

\begin{tabular}{lcccccc}
\hline Simulation No. & Microphysics & PBL scheme & Land surface model & Longwave radiation & Shortwave radiation & Convective scheme \\
\hline Simulation 1 & WSM3 & YSU & Noah & RRTM & CAM & Kain-Fritsch \\
Simulation 2 & WSM3 & YSU & Noah & CAM & CAM & Kain-Fritsch \\
Simulation 3 & WSM3 & YSU & RUC & RRTM & CAM & Kain-Fritsch \\
Simulation 4 & WSM3 & YSU & RUC & CAM & CAM & Kain-Fritsch \\
Simulation 5 & Morrison & YSU & Noah & RRTM & CAM & Kain-Fritsch \\
Simulation 6 & Morrison & YSU & Noah & CAM & CAM & Kain-Fritsch \\
Simulation 7 & Morrison & YSU & RUC & RRTM & CAM & Kain-Fritsch \\
Simulation 8 & Morrison & YSU & RUC & CAM & CAM & Kain-Fritsch \\
Simulation 9 & Morrison & MYNN3 & Noah & RRTM & CAM & Kain-Fritsch \\
Simulation 10 & Morrison & MYNN3 & Noah & CAM & CAM & Kain-Fritsch \\
Simulation 11 & Morrison & MYNN3 & RUC & RRTM & CAM & Kain-Fritsch \\
Simulation 12 & Morrison & MYNN3 & RUC & CAM & CAM & Kain-Fritsch \\
\hline
\end{tabular}

cover, and frozen soil physics. The main difference between Noah and RUC is the treatment of snow; the Noah LSM includes fractional snow cover while the RUC LSM includes multilayer snow.

Longwave radiation schemes most suited for regional climate simulations are the Rapid Radiative Transfer Model (RRTM) scheme (Mlawer et al. 1997) and the Community Atmosphere Model (CAM) longwave radiation scheme (Collins et al. 2004, 102-143). Both of these schemes have been investigated in this study. The CAM shortwave radiation scheme (Collins et al. 2004) is used in all simulations. CAM is the most suitable shortwave scheme for climate simulations as its ozone distribution varies during the simulation according to monthly zonal-mean climatology data.

Two microphysics schemes have been examined representing opposite ends of the spectrum in terms of complexity and computational cost. The WRF singlemoment three-class (WSM3) scheme (Hong et al. 2004) is considered one of the simpler and computationally least expensive schemes, whereas the Morrison twomoment scheme (Morrison et al. 2009) is one of the more advanced schemes and is computationally much more demanding.

The two planetary boundary layer schemes chosen for study are the widely used Yonsei University (YSU) scheme (Hong et al. 2006), and the Mellor-Yamada Nakanishi and Niino level 3.0 (MYNN3) scheme (Mellor and Yamada 1982; Nakanishi and Niino 2004). In an attempt to get an indication of the sensitivity of WRF to the choice of PBL scheme, we selected MYNN3 because it is significantly different from YSU.

In this investigation, the widely used Kain-Fritsch (Kain and Fritsch 1990; Kain 2004) convective scheme and the CAM longwave radiation scheme and were employed in all simulations. At a grid spacing of $0.44^{\circ}$, convection is not resolved explicitly and must be parameterized in the convective parameterization schemes
(CPSs). It is well known (e.g., Zhang et al. 1994) that the CPS scheme chosen will be at least as important as the microphysics scheme selected. There are several reports published on the sensitivity of WRF to the choice of CPS (Molinari and Dudek 1992; Wang and Seaman 1997; Mercader et al. 2010). Rather than repeating their work, we have decided to build on these results by adopting the more successful Kain-Fritsch convective scheme in this study.

\section{c. Gridded datasets}

\section{1) ERA-INTERIM}

ERA-Interim provided the initial conditions, lateral boundaries, and sea surface temperatures. The data were obtained from the ECMWF data server on a fixed grid of $1.5^{\circ}$ (Dee et al. 2011). ERA-Interim uses 4D variational analysis on a spectral grid with triangular truncation of 255 waves (corresponding to $\sim 80 \mathrm{~km}$ ) and a hybrid vertical coordinate system with 60 levels.

\section{2) OBSERVATIONAL DATASETS (E-OBS AND CRU)}

We compared WRF outputs with two different gridded observational datasets: E-OBS (Haylock et al. 2008; van den Besselaar et al. 2011) and CRU TS 3.0 (Mitchell and Jones 2005). E-OBS is a high-resolution gridded dataset of surface temperature and precipitation over the European terrestrial domain for the period 1950-2006 (Haylock et al. 2008). Recently, the dataset has been extended to include mean sea level pressure over the domain (van den Besselaar et al. 2011). It has a temporal resolution of $24 \mathrm{~h}$ and it is available at grid spacings of 25 and $50 \mathrm{~km}$ on both the regular latitude-longitude grid and rotated-pole grid. The data used in this study were obtained on a regular latitudelongitude grid. CRU TS3.0 represents a gridded database $\left(0.5^{\circ} \times 0.5^{\circ}\right)$ of monthly climate observations for 


\section{(a) Winter}
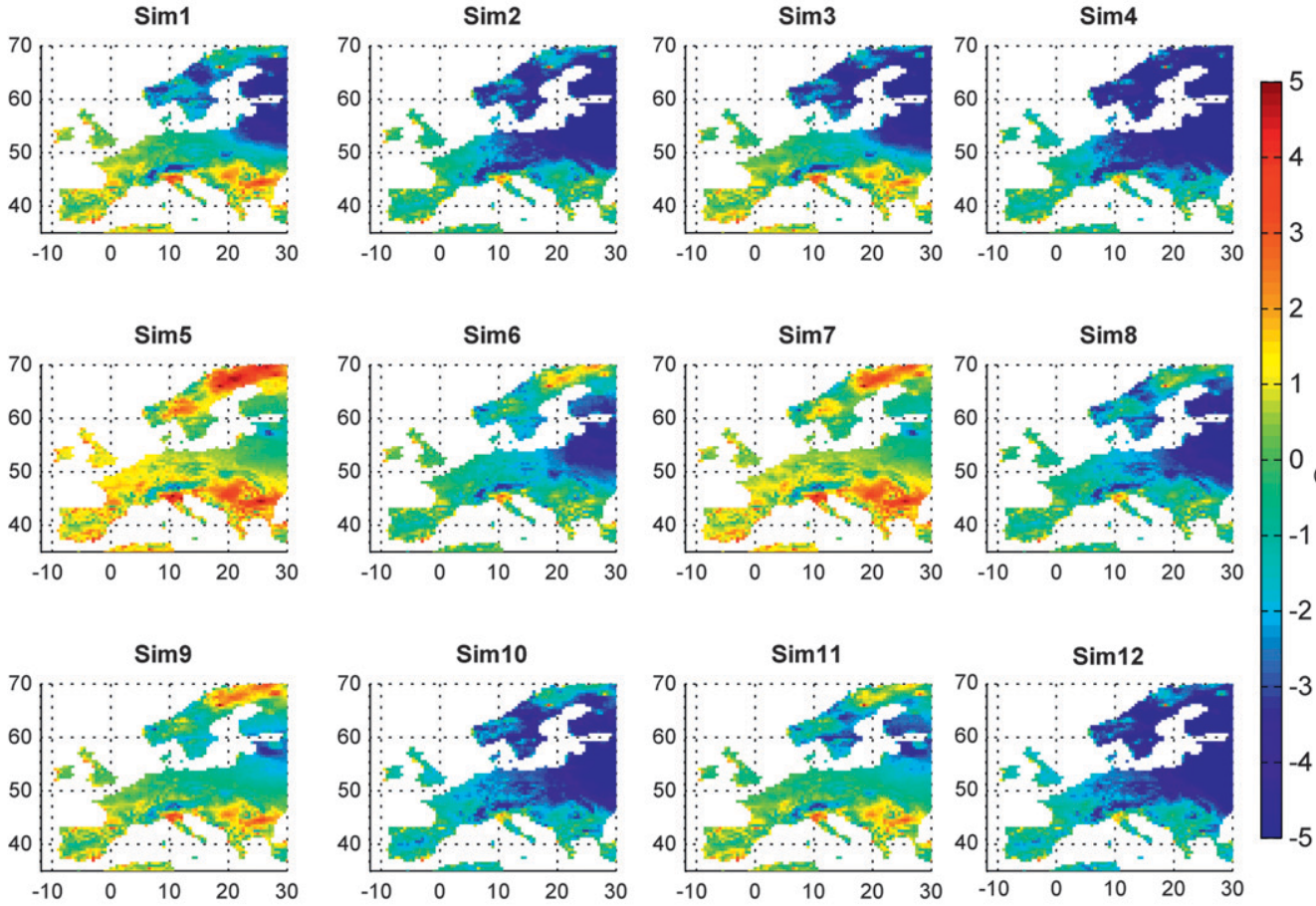

(b) Summer
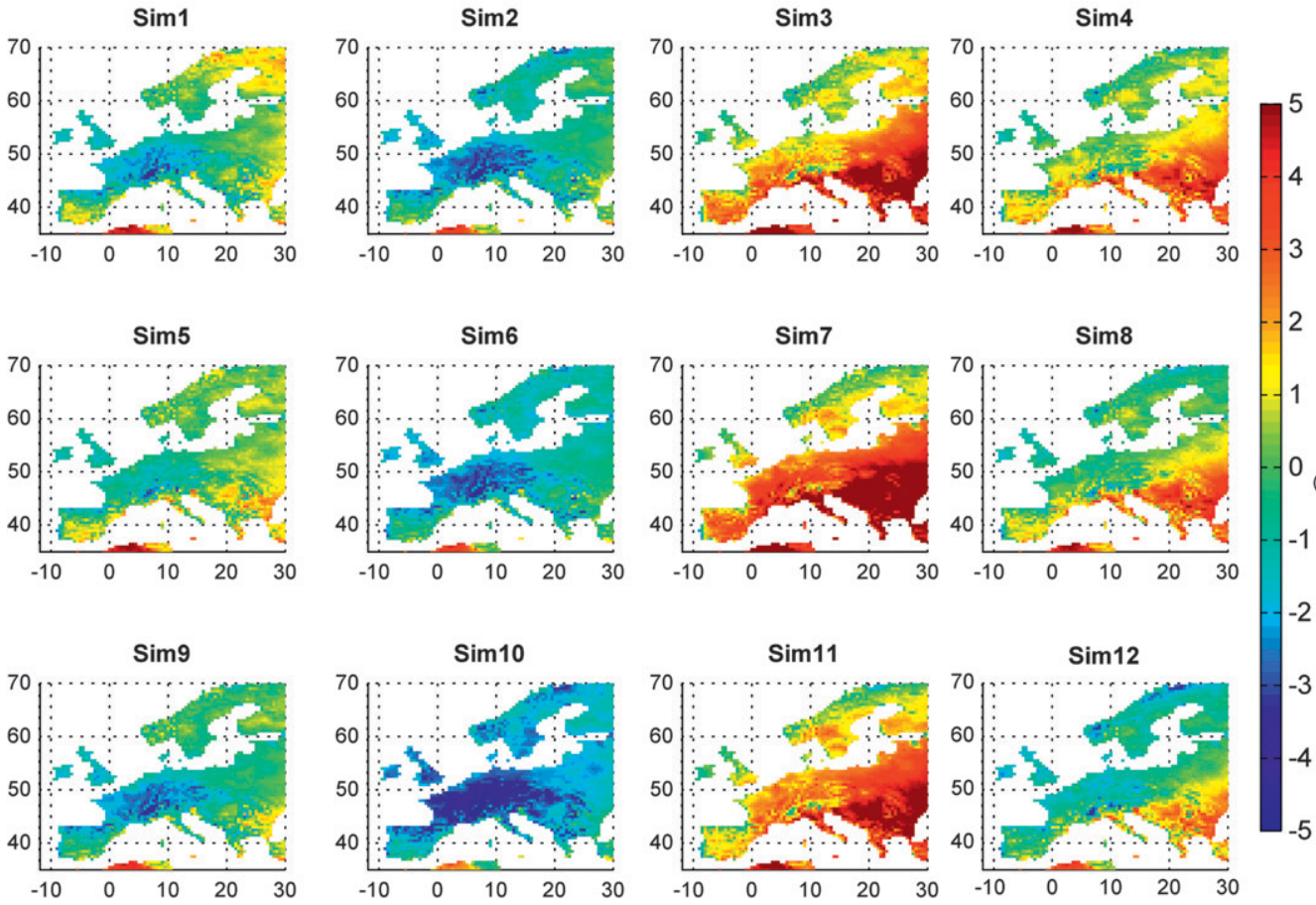

FIG. 2. (a). Plot of the bias (WRF - EOBS) in the mean winter (DJF) surface air temperature $\left({ }^{\circ} \mathrm{C}\right)$ at $2 \mathrm{~m}(\mathrm{~T} 2)$ in the period 1990-95 for all 12 simulations. (b). As in (a), but for summer (JJA). 
(a) Winter

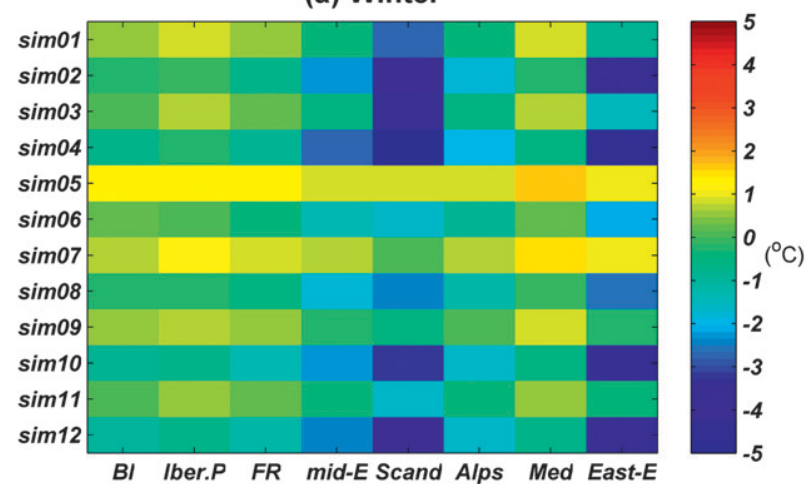

(b) Summer

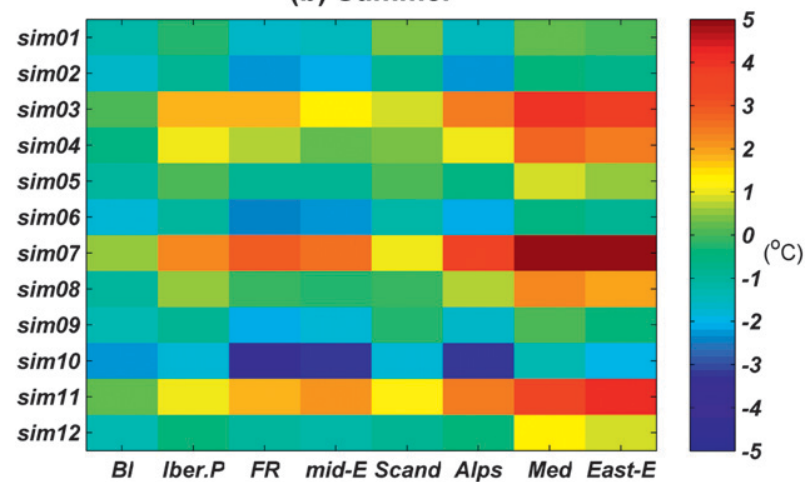

FIG. 3. Bias in the mean surface air temperatures (T2) relative to E-OBS for each of the 12 WRF simulations averaged over 1990-95 by subregion (shown in Fig. 1) in (a) winter and (b) summer.

temperature and precipitation for the period 1901-2002 over the global land surface constructed from meteorological stations and is publicly available from the British Atmospheric Data Centre (http://badc.nerc.ac. uk/). Comparisons of WRF with CRU and WRF with EOBS produced similar results. For clarity in this report, we present only one of these studies and we have chosen E-OBS in preference to CRU TS 3.0 data as it has a higher temporal resolution and includes mean sea level pressure.

\section{Simulation results}

Before commencing our detailed study of the $12 \mathrm{WRF}$ simulations listed in Table 1, we compared WRF output with ERA-Interim data in order to test WRF's ability to reliably reproduce its parent data. Key atmospheric variables such as mean sea level pressure, the $500-\mathrm{hPa}$ temperature, and geopotential height were examined. The time-averaged values of these three parameters were compared with ERA-Interim values for bias throughout the entire domain (not shown). WRF reproduced the average values of all three variables to within $\pm 1 \%$

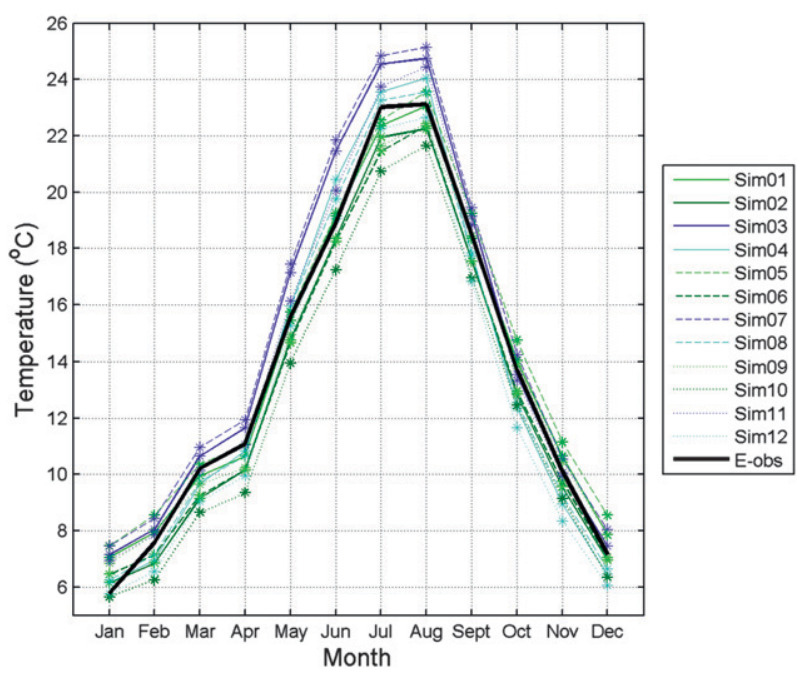

FIG. 4. Mean monthly surface air temperature for all 12 simulations and E-OBS (black line) over the 6-yr period for Iberian Peninsula. Simulations represented in green use the Noah land surface model, while those in blue use the RUC LSM.

with the regions farthest from the domain boundary showing the greatest difference as expected.

\section{a. Surface temperature}

Figures $2 \mathrm{a}$ and $2 \mathrm{~b}$ show bias (WRF - EOBS) in the surface air temperature modeled by WRF for winter [December-February (DJF)] and summer [June-August (JJA)] respectively averaged over the 1990-95 period. In winter (Fig. 2a, LSM does not show a strong influence with (the plots in) columns 1 and 2 (which use NOAH LSM) more or less repeated in columns 3 and 4 (RUC LSM). The quite marked differences between columns 1 and 2 (and also between columns 3 and 4) are the result of different LWR schemes, which appear to have a strong influence. Columns 1 and 3 use the RRTM LWR scheme, while columns 2 and 4 use CAM. The clear differences between row 1 and row 2 are due to the change from WSM3 to the Morrison microphysics scheme. Row 3 also uses Morrison microphysics but differs from row 2 in the PBL scheme used. In contrast, LSM has a substantial influence in the summer results shown in Fig. 2b, with columns 3 and 4 standing out quite markedly from columns 1 and 2 . Some evidence of the LWR influence still persists, but it is now overshadowed by the LSM influence. In summer, microphysics and PBL schemes do not seem to have a strong influence, as indicated by relatively small changes between the three rows in Fig. $2 b$.

Over such a large domain, no single combination of parameterizations yields optimal results. To facilitate a comparison of all 12 simulations for surface air 
(a)

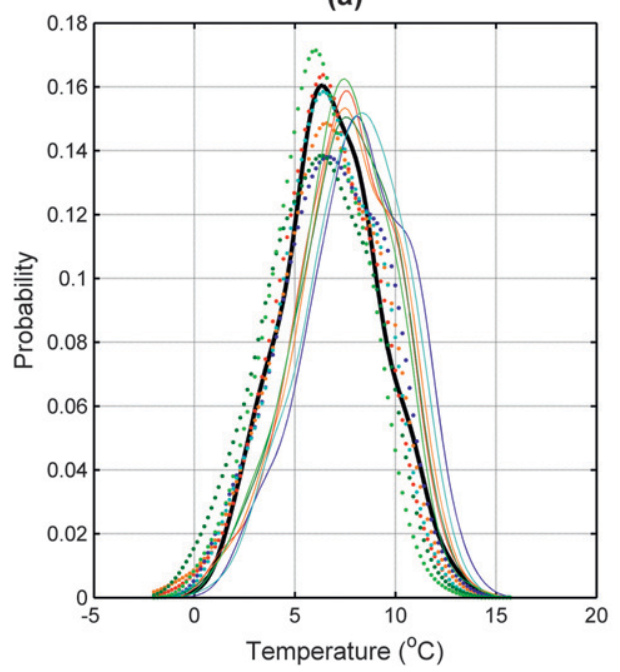

(b)

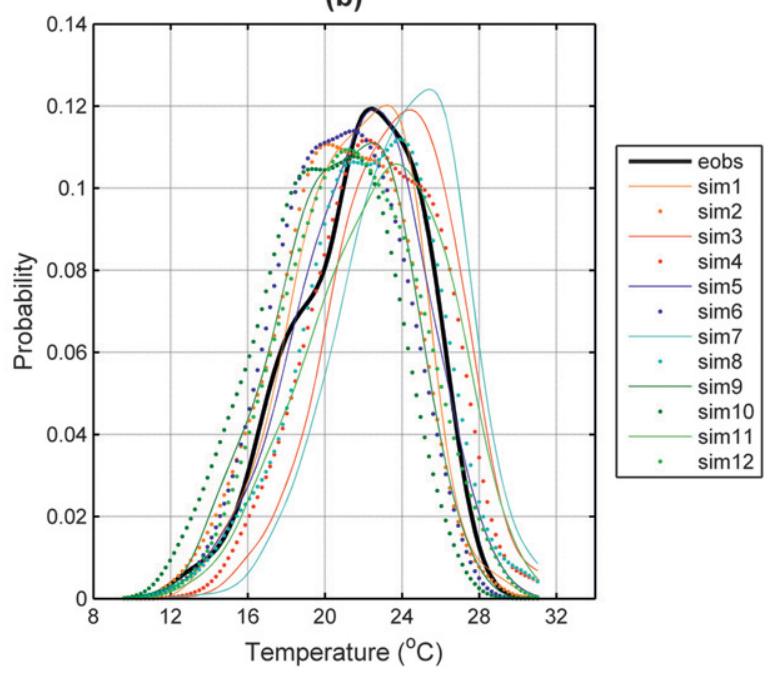

FIG. 5. Plot of the PDF of surface air temperature (T2) for all 12 simulations for the Iberian Peninsula in (a) winter and (b) summer.

temperature we adopted the matrix representation of the Rockel regions used by Christensen and Christensen (2007). Figures $3 \mathrm{a}$ and $3 \mathrm{~b}$ show the winter and summer bias, respectively, in surface air temperatures for each of the 12 WRF simulations averaged over 1990-95. In winter, simulations ( 9 and 11) with the RRTM longwave radiation scheme, the Morrison two-moment microphysics scheme, and the MYNN3 PBL scheme have the least bias across all geographical regions. Summer biases show clearly that simulations using the Noah land surface model $(1,2,5,6,9$, and 10) have the least offset. Biases are more easily observed in mean monthly surface temperatures, of which Fig. 4 for the Iberian Peninsula is a typical example. It shows that the span of WRF simulations include the E-OBS values over the 6 -yr period. Simulations using Noah LSM (colored green) exhibit lower bias in both winter and summer compared with those in which RUC are used (blue). Geographically, biases are greatest over Scandinavia in winter while the Mediterranean and eastern Europe have the largest biases in summer. Several regional models for Europe have shown a winter bias in Scandinavia (Jacob et al. 2007).

Probability density functions of surface air temperature in winter for the 12 simulations are compared with the corresponding E-OBS plot for the Iberian Peninsula in Fig. 5a. The PDFs of the simulations agree remarkably well with the observations and are consistent with the bias plot of the Iberian Peninsula shown in Fig. 3a. Differences between simulations are not very pronounced. On the other hand, PDFs of the summer simulations in Fig. $5 \mathrm{~b}$ show a greater spread that includes the E-OBS results in the center of the spread. The general patterns shown in Figs. 5a and $5 \mathrm{~b}$ are repeated in the simulations of the seven other subregions, and they provide additional information about the offsets that are evident in Figs. $3 a$ and $3 b$.

A Taylor diagram (Taylor 2001) showing the correlation, RMSD, and standard deviation for each simulation over the Iberian Peninsula is shown in Fig. 6. The

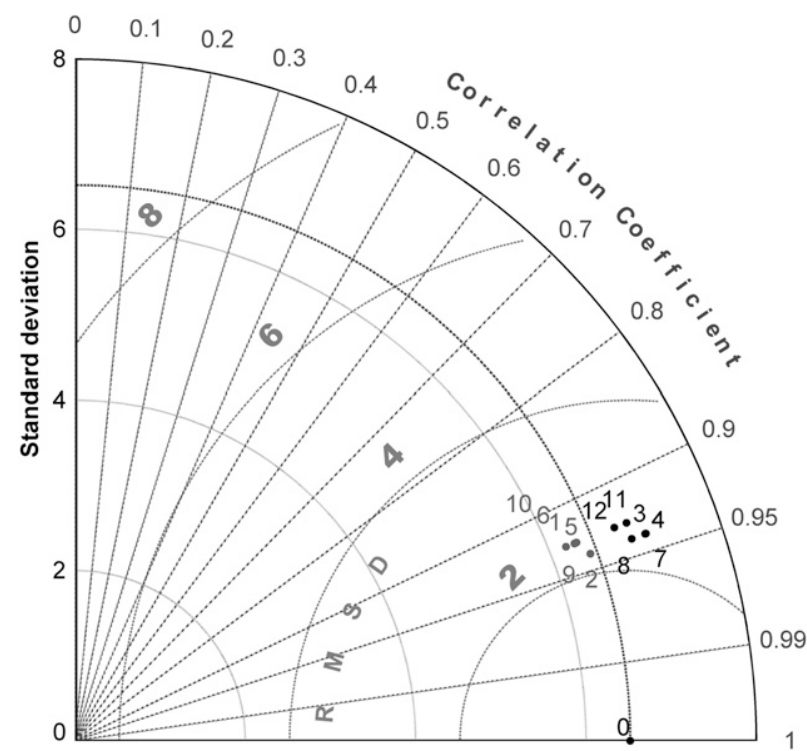

FIG. 6. Taylor diagram showing correlation coefficient, RMSD, and standard deviation of surface air temperature relative to E-OBS for the 12 simulations listed in Table 1 over the Iberian Peninsula. Simulations represented by gray points use the Noah land surface model, while those in black use the RUC LSM. 


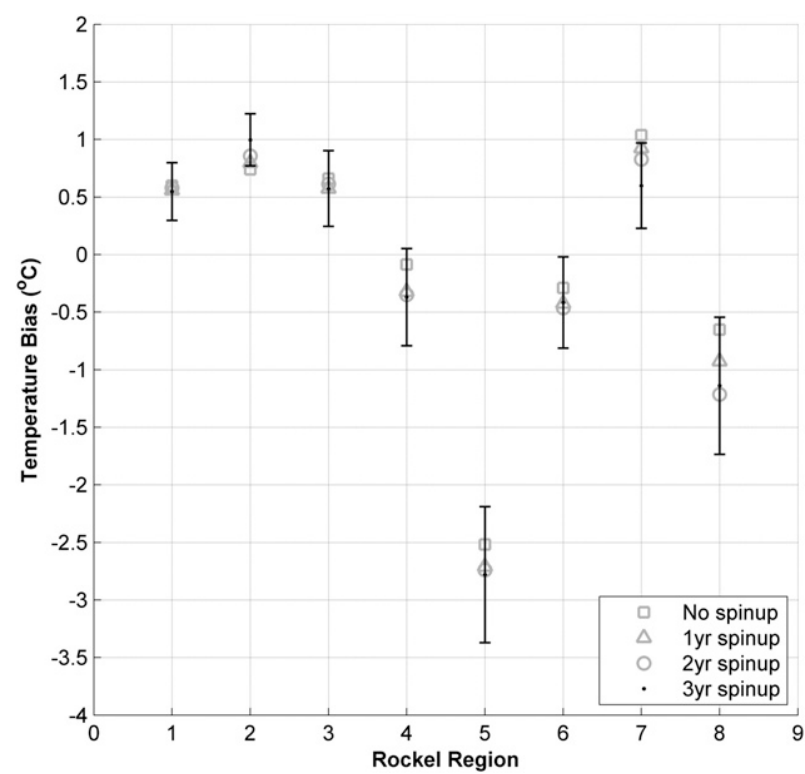

FIG. 7. Plot of winter bias in surface air temperature in the case of simulation 1 for simulations with $0-, 1-, 2-$, and 3-yr spinup for the eight Rockel regions shown in Fig. 1. The error bar represents the $95 \%$ confidence level on the 3 -yr spinup.

general pattern shown in this plot, with the simulations divided into two distinct groups lying broadly speaking along a radius, is repeated in the remaining seven Rockel regions (not shown). The first group (simulations 1, 2, 5, 6, 9, and 10; colored gray) use the Noah LSM and lie inside and closer to the dashed arc on the diagram, indicating that their standard deviations are in better agreement with the E-OBS standard deviation than the second group (simulations 3, 4, 7, 8, 11, and 12, colored black), which use the RUC LSM. Simulation 2, which uses the Noah land surface model, CAM longwave radiation, WSM3 microphysics, and YSU planetary boundary layer, shows closest agreement with observations in this subregion.

Since studies of the type described here frequently employ a "spinup" period, (e.g., Yu et al. 2010), we examined the effect of using a spinup period on the results of the WRF output for all three state variables considered. Spinup times of $0,1,2$, and 3 years were considered in the case of winter bias, summer bias, correlation coefficient and standard deviation. Figure 7 showing the winter bias in surface temperature for simulation 1 is a typical example of the output of this investigation. The error bars represent the $95 \%$ confidence level of the 3-yr spinup values. Based on the results of this examination, we deduce that the results without spinup are not significantly different from those that did employ a spinup period. We present the results for simulations that used a 1-yr spinup as a compromise between including some spinup period, while maximizing the length of time under investigation ( $6 \mathrm{yr}$ ).

In summary, our results for temperature show a significant dependence on the land surface model with Noah superior to RUC particularly in summer. This result supports the finding of Jin et al. (2010), who carried out WRF simulations using four land surface schemes over the western United States for the period 1 October 1995 through 30 September 1996. The four LSM schemes included the soil thermal diffusion (STD) scheme and the sophisticated NCAR Community Land Model version 3 (CLM3) scheme as well as the two schemes used in this study. They found that land surface processes strongly affected temperature simulations over the domain in question. Our results show that surface air temperatures simulated by WRF are less sensitive to microphysics and PBL parameterizations than to longwave radiation scheme and land surface scheme. The combination of CAM longwave radiation and NOAH LSM is slightly better than the other combinations examined.

\section{b. Precipitation}

Biases in the mean daily precipitation of WRF simulations from E-OBS (WRF - EOBS) are shown in Figs. $8 \mathrm{a}$ and $8 \mathrm{~b}$ for winter and summer, respectively. It is difficult to single out any one of the 12 winter simulations as being superior to the other 11. Differences are far more obvious in summer with the 12 simulations clearly divided by LSM. Simulations that use Noah LSM (columns 1 and 2) have a greater tendency to show a positive bias in mean daily precipitation than those using the RUC (columns 3 and 4). LWR has a smaller but still noticeable effect as illustrated by the difference between columns 1 and 2 (and also between columns 3 and 4). Microphysics has a comparable effect on the simulation to LWR, but the effect of the two different PBL schemes appears negligible.

Figure 9 uses the matrix representation of the Rockel regions to allow a more detailed comparison of the bias in daily precipitation for all 12 simulations in winter and summer. With the exception of the British Isles and Scandinavia subregions, all simulations overestimate winter precipitation. The winter pattern in Fig. 9a is dominated by regional differences with relatively little distinction between the different simulations. These results are consistent with Jin et al. (2010), who reported that precipitation was overestimated by WRF with all four land surface schemes in their study and it did not show a close relationship with land surface processes. In contrast, the summer pattern in Fig. 9b shows a strong simulation influence dominated by the land surface model; simulations that use the RUC LSM $(3,4,7,8,11$, 


\section{(a) Winter}
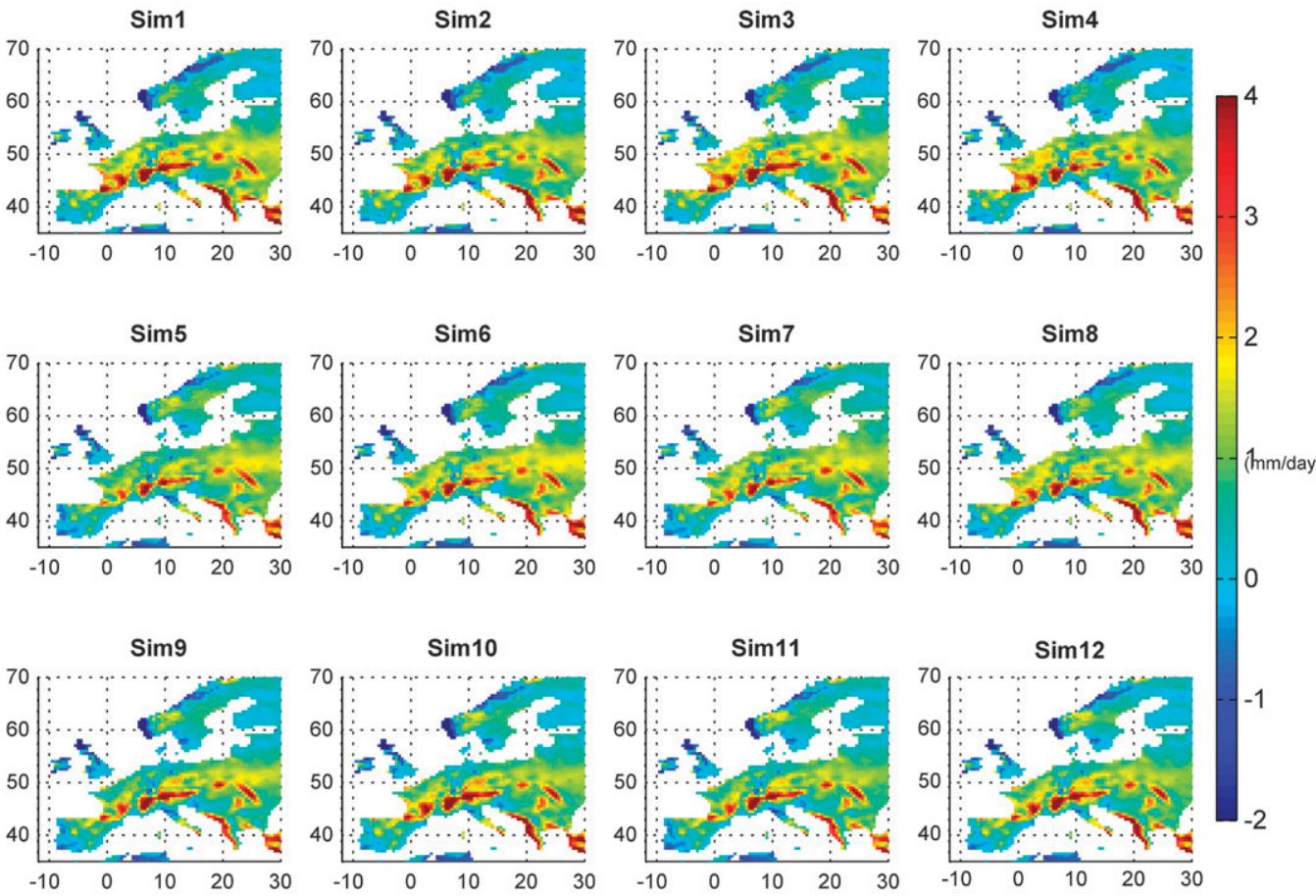

\section{(b) Summer}
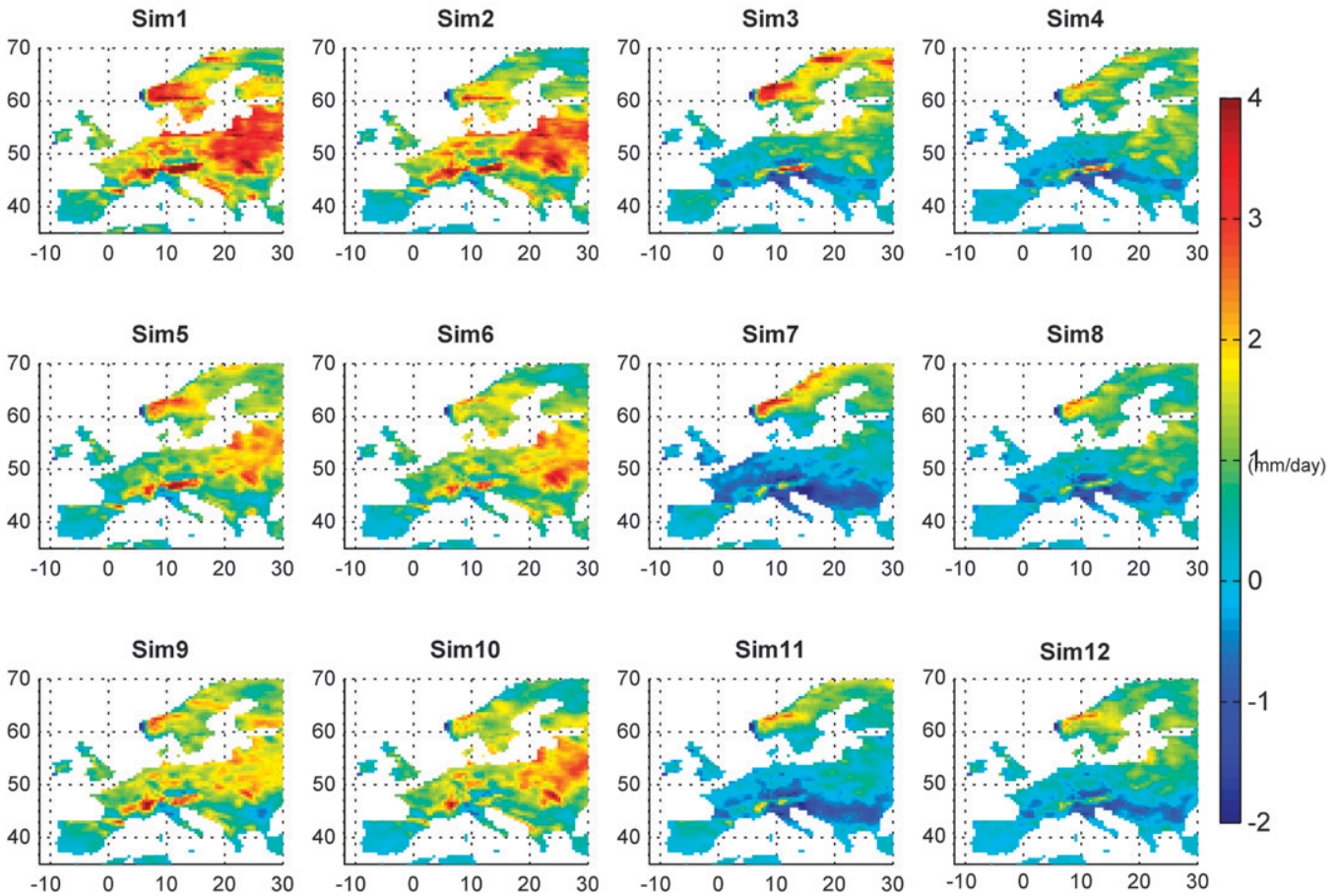

FIG. 8. (a). Plot of the bias (WRF - EOBS) in the mean winter (DJF) daily precipitation ( $\mathrm{mm} \mathrm{day}^{-1}$ ) in the period 1990-95 for all 12 simulations. (b) As in (a), but for summer (JJA). 
(a) Winter

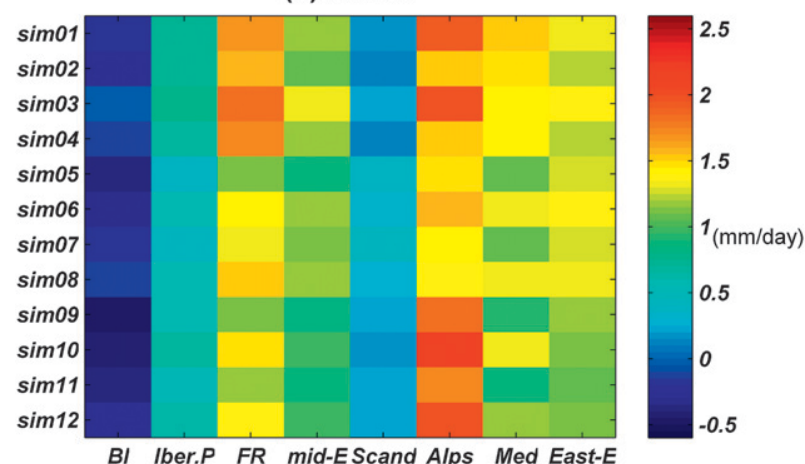

(b) Summer

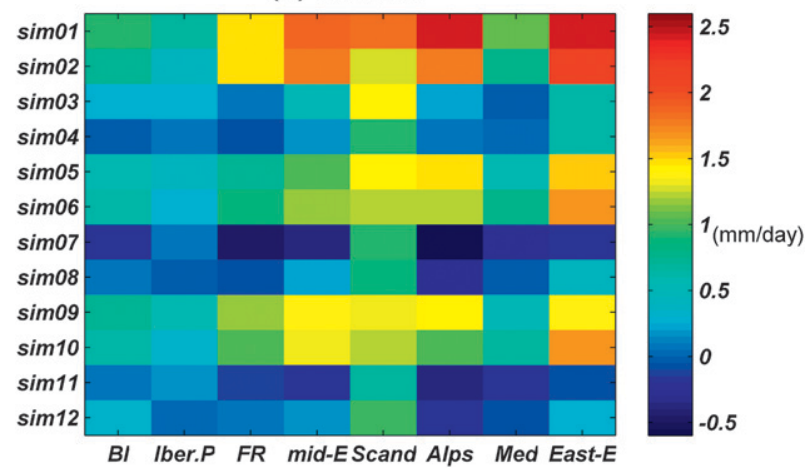

FIG. 9. Bias (WRF-EOBS) $\left(\mathrm{mm} \mathrm{day}^{-1}\right)$ in daily mean precipitation for each of the 12 WRF simulations averaged over 1990-95 by subregion (shown in Fig. 1) in (a) winter and (b) summer.

and 12) have a much smaller bias than those using the Noah scheme. A high-resolution study of large-scale cold-pooling events over southern Georgia (United States) using the Noah and RUC parameterizations by Prabha et al. (2011) found that LSM schemes play a significant role in the accuracy of mesoscale numerical models by accounting for the exchange of energy and water between the soil and the atmosphere. They noted the importance of these results for regional downscaling.

The second most influential parameterization on precipitation in this study is the microphysics scheme. Of the two schemes examined here, WSM3 has a larger bias than the Morrison scheme. These results agree quite well with Jankov et al. (2011), who examined five different microphysical schemes (Lin, WSM6, Thompson, Schultz, and double-moment Morrison) in a WRF simulation study of a significant precipitation event that occurred along the California coast in December 2005. All schemes exhibited comparable performance when using accumulated precipitation and other commonly used observational data. The Lin and Schultz schemes showed the lowest prediction skill, while the Morrison scheme was only slightly better than either WSM6 or

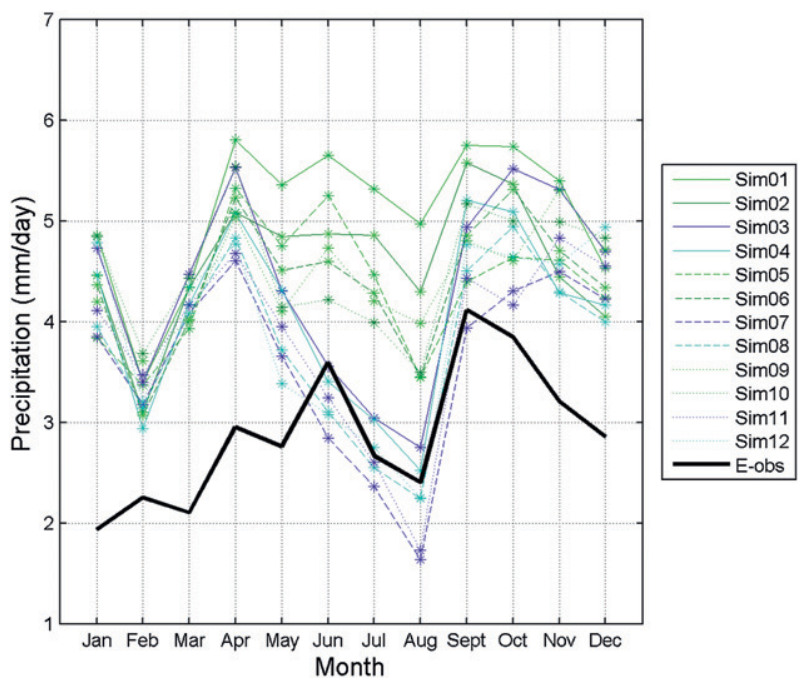

FIG. 10. Daily mean precipitation by month for the $12 \mathrm{WRF}$ simulations and E-OBS dataset (black line) over the 6-yr period for the Alps subregion.

Thompson in terms of RMSE. By comparing synthetic satellite images using all five microphysics schemes with observational data from Geostationary Operational Environmental Satellite 10 (GOES-10), Jankov et al. (2011) found that simulations using WSM6 and Morrison produced cloud coverage patterns closest to observations.

Figures $9 \mathrm{a}$ and $9 \mathrm{~b}$ show that averaged daily precipitation levels appear to be relatively insensitive to the longwave radiation scheme chosen, with CAM holding a slight advantage over RRTM. The distinction between summer and winter patterns shows up clearly in Fig. 10 (Alps subregion), which is a typical example of the mean daily precipitation for each month over the 6-yr period. Simulations that use the RUC land surface model (blue) show good agreement with observations in summer. PDFs of the simulations are compared with the corresponding plot for the observations for the Alps subregion in Figs. 11a and $11 \mathrm{~b}$ for winter and summer, respectively. PDFs of the simulations for winter show very few differences and generally agree reasonably well with observations. The range of PDFs in the simulations is much greater for summer and E-OBS falls comfortably in the middle of this range. A representative Taylor diagram of precipitation is shown for the Alps region in Fig. 12. It is immediately obvious that the correlation coefficients are much lower and that the RMSD values are substantially larger for precipitation than for surface air temperature (cf. Figs. 12 and 6). The range of variability of all simulations is comparable to the observations, albeit greater in all instances. In general, Fig. 12 shows that simulations using the RUC scheme tend to be 
(a)

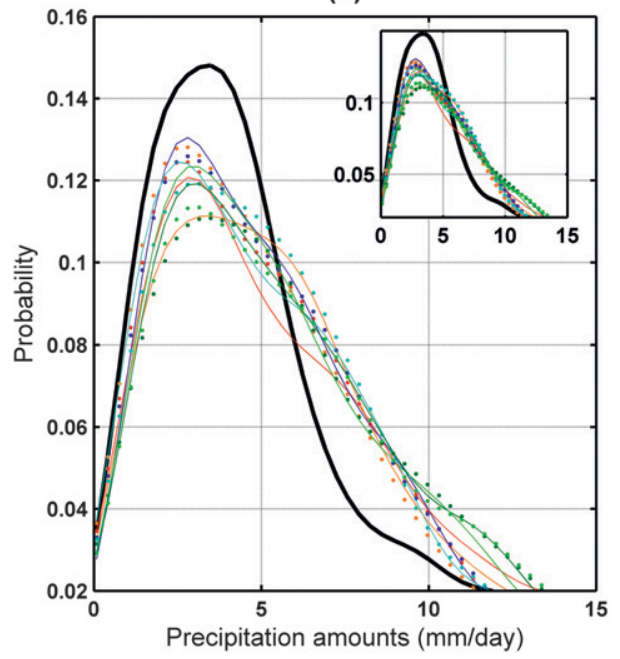

(b)

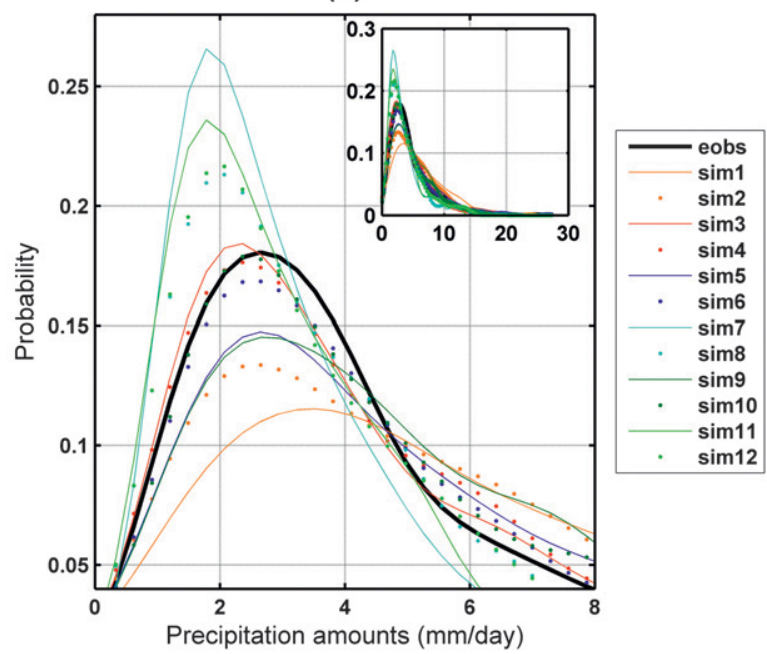

FIG. 11. Plot of the PDF of daily mean precipitation (PR) for all 12 simulations for the Alps subregion in (a) winter and (b) summer. For clarity, the main part of the figure shows a zoomed-in region of the full PDF in the inset.

slightly closer to the observations than those using the Noah scheme, with simulation 7 having statistical values that best match E-OBS precipitation.

\section{c. Mean sea level pressure}

Biases in WRF mean sea level pressure compared with E-OBS (WRF - E-OBS) over the 6-yr period are shown in Figs. 13a and 13b for winter and summer, respectively. WRF models the seasonal values of MSLP to within $\pm 1 \%$ of the E-OBS data. This result is further illustrated in the matrix plots of the Rockel regions (Figs. 14a,b) and the monthly mean plots (Fig. 15). It is also clear from all of these figures that WRF consistently underestimates MSLP in both winter and summer, with the largest bias occurring in the winter season in the Alps and eastern Europe. The matrix form plot in Fig. $14 \mathrm{a}$ is dominated by differences between regions rather than by simulation. Figure 14b shows evidence of distinction on the basis of simulation number but regional differences remain strong. Longwave radiation is the parameterization that appears to have greatest influence on the pattern, with simulations using CAM marginally ahead of those using RRTM.

The consistent underestimation in the WRF simulations $(<1 \%)$ is well illustrated in Fig. 15, which shows the average MSLP by month for all simulations and for the observations (black line) over the 6-yr period for France. PDFs of the MSLP from simulations are compared with observations for France in winter and summer in Figs. 16a and 16b, respectively. The winter plot illustrates the deviation of all simulations from the observations, while the summer plot shows much better agreement with observations in both the distribution and in overall shape. A Taylor diagram of MSLP for the 12 simulations over France is shown in Fig. 17. All of the simulations are bunched closely together with correlation coefficients in the range $0.7-0.8$, RMSD values of the order of $6 \mathrm{hPa}$ or greater and slightly larger variability than the E-OBS values.

A Taylor diagram of all three variables for the mid-Europe region, which is representative of all eight Rockel regions, is shown in Fig. 18. To represent the

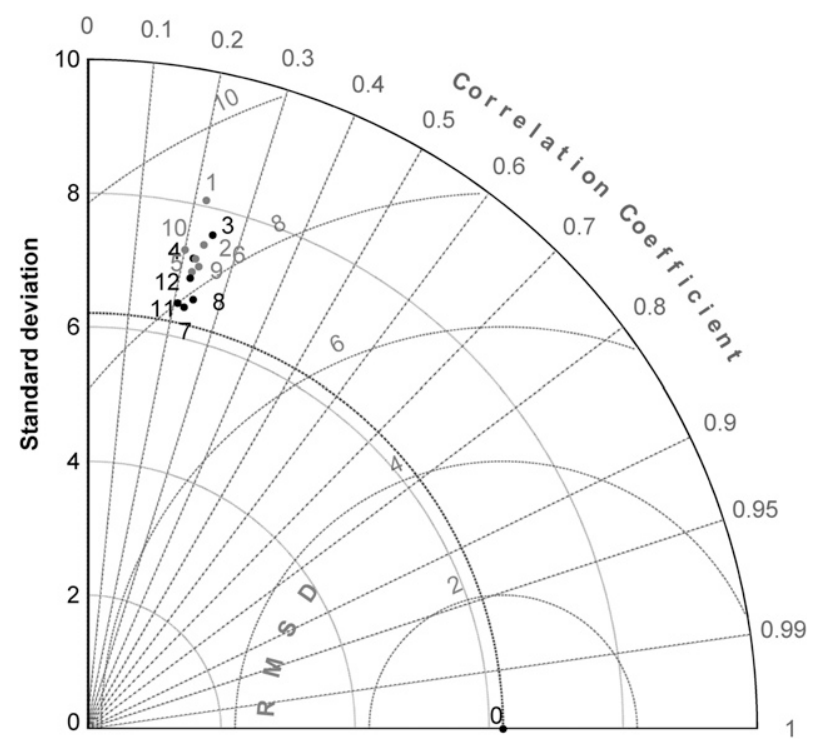

FIG. 12. Taylor diagram showing correlation coefficient, RMSD, and standard deviation of daily precipitation relative to E-OBS of the 12 simulations listed in Table 1 for the Alps subregion. 


\section{(a) Winter}
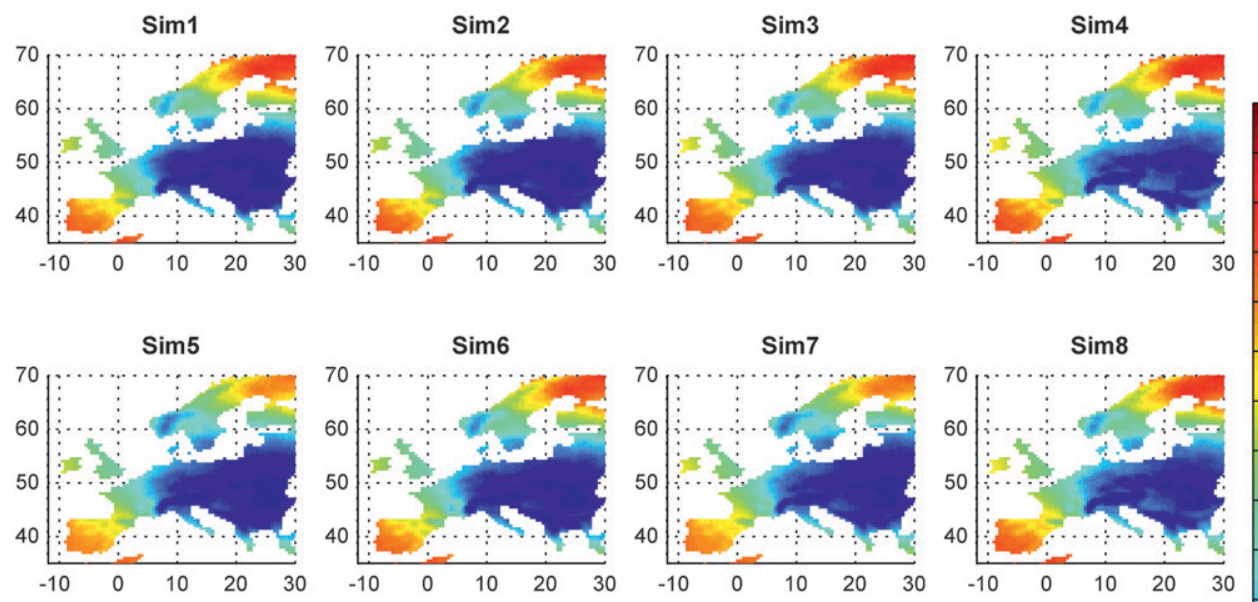

2
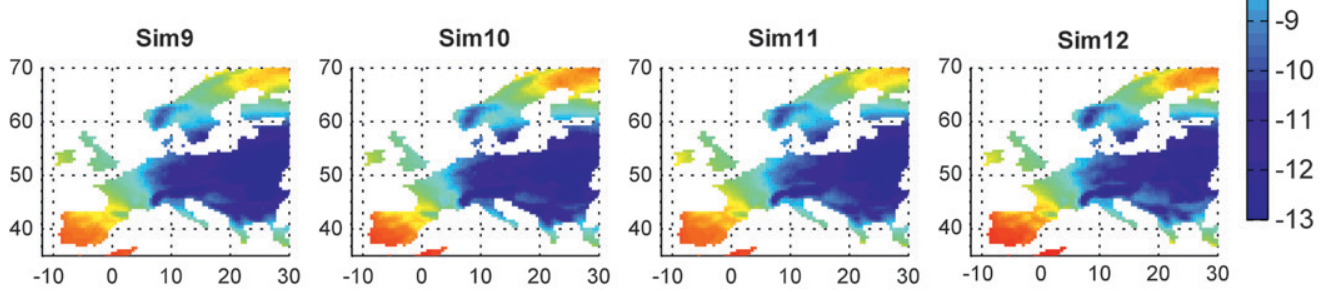

\section{(b) Summer}
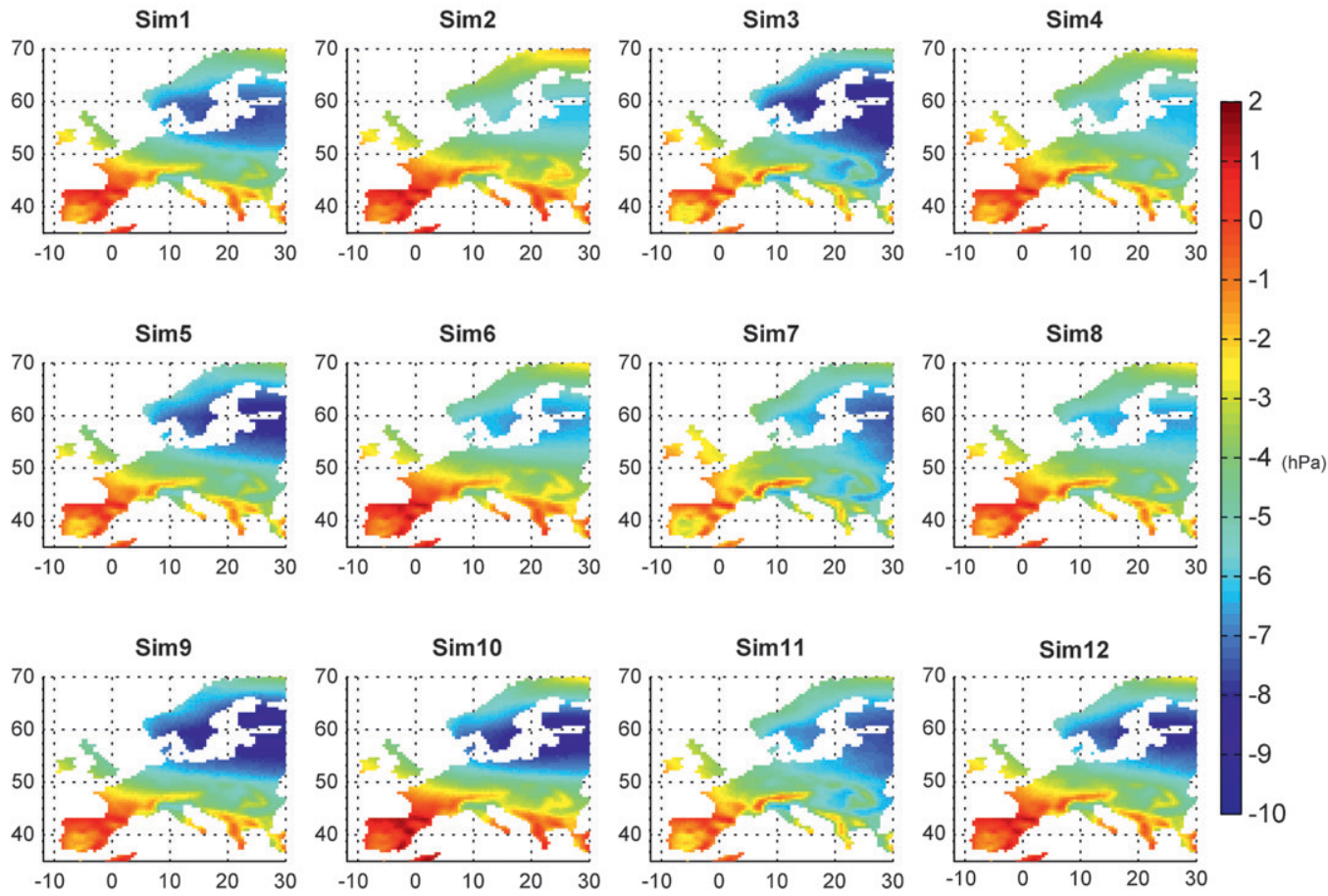

FIG. 13. (a). Plot of the bias (WRF - EOBS) in the average winter (DJF) mean sea level pressure (hPa) in the period 1990-95 for all 12 simulations. (b). As in (a), but for summer (JJA). 
(a) Winter

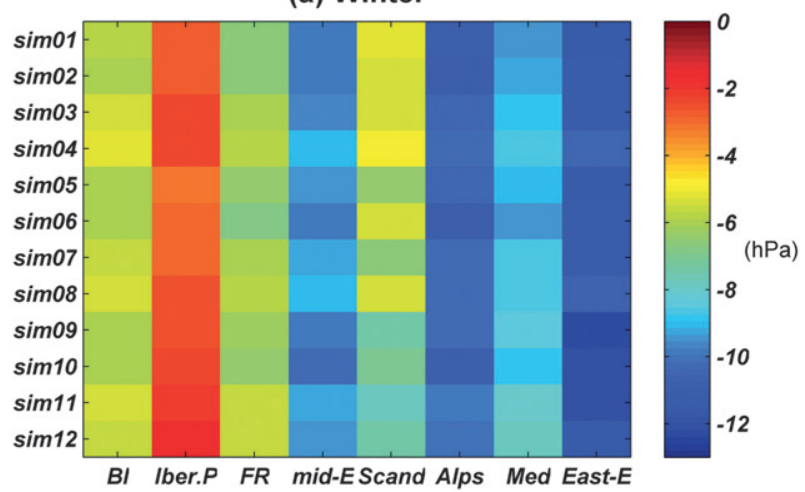

(b) Summer

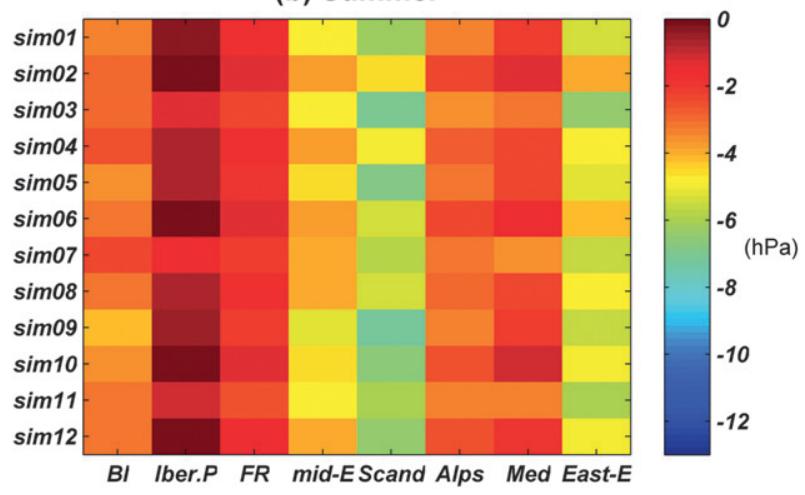

FIG. 14. Bias in mean sea level pressure relative to E-OBS for each of the 12 WRF simulations averaged over 1990-95 by subregion (shown in Fig. 1) in (a) winter and (b) summer.

three variables on a single plot, the standard deviation of each modeled parameter has been normalized to the standard deviation of the observed values. It is immediately evident from this figure that, of the three variables considered in this study, WRF performs best when modeling surface air temperature; WRF is weakest when modeling precipitation and is intermediate between these two extremes when modeling MSLP. This plot also shows that MSLP is sensitive to the PBL scheme chosen, with simulations $9,10,11$, and 12 (all of which use the MYNN3 PBL scheme) clearly separated from, and with higher standard deviations than, the other eight simulations that use the YSU PBL scheme. This pattern can also be discerned in Fig. 17 for the France subregion and is evident in some extent to all subregions.

For each variable examined, simulations 6 and 8 tend to capture patterns in observed data better than other simulations. Taylor diagrams of these simulations for all eight geographical regions are shown in Figs. 19a and 19b. It is evident from the large spread in correlation coefficient and RMSD of MSLP in these plots that WRF's ability to model MSLP depends more on the region

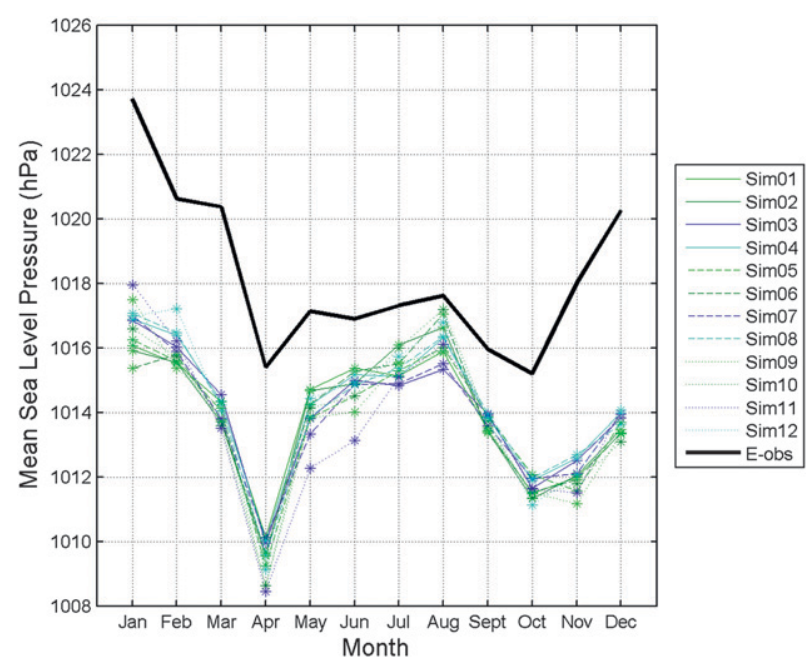

FIG. 15. Mean sea level pressure by month for the 12 WRF simulations and E-OBS (black line) over the 6-yr period for the France subregion.

than any other variable. This contrasts with the two tightly bunched groups of MSLP in Fig. 17. WRF appears to be most successful in modeling regions 1 (British Isles) and 2 (Iberian Peninsula), whereas it seems to be weakest in regions 7 (Mediterranean) and 8 (eastern Europe).

\section{Summary}

This investigation of the sensitivity of surface variables modeled by WRF to parameterization schemes used for microphysics, land surface, planetary boundary layer, and longwave radiation has shown the following:

- WRF is capable of modeling surface air temperature across several very different climatic regions in the European domain with small biases in the average values over the 6-yr period and high correlation coefficients in all simulations.

- WRF surface air temperatures show greatest sensitivity to land surface model with simulations using Noah closer to observations than those using RUC particularly in summer. Temperature shows some sensitivity to longwave radiation in winter only, but very little sensitivity to either microphysics or PBL.

- Modeling precipitation is problematic for WRF with biases of up to $100 \%$ at certain times of the year, and generally low temporal correlation coefficients $(0.2<$ $R<0.3$ ) with observations.

- WRF precipitation is sensitive to the land surface model especially in summer with simulations using RUC ahead of of those using Noah. Precipitation output is sensitive to longwave radiation and microphysics in 
(a)

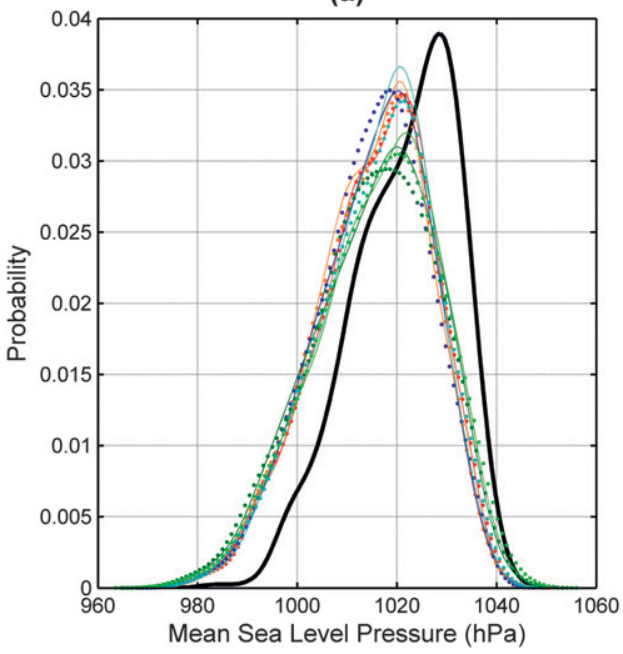

(b)

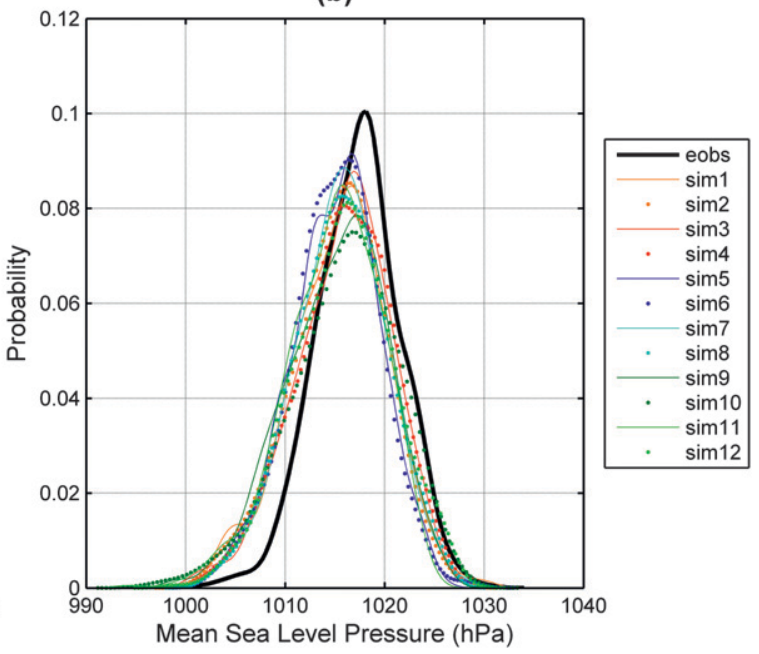

FIG. 16. Plot of the PDF of mean sea level pressure for all 12 simulations for the France subregion in (a) winter and (b) summer.

summer but not to such a large extent as the land surface model. Precipitation shows negligible sensitivity to the PBL scheme chosen.

- MSLP is modeled well by WRF with only a small negative bias $(<1 \%)$, which is consistent across all simulations. Temporal correlation coefficients are relative high, typically in the range $0.7<R<0.8$. MSLP output appears to be insensitive to any of the four parameterizations in winter but shows slight sensitivity to longwave radiation in summer. Simulations

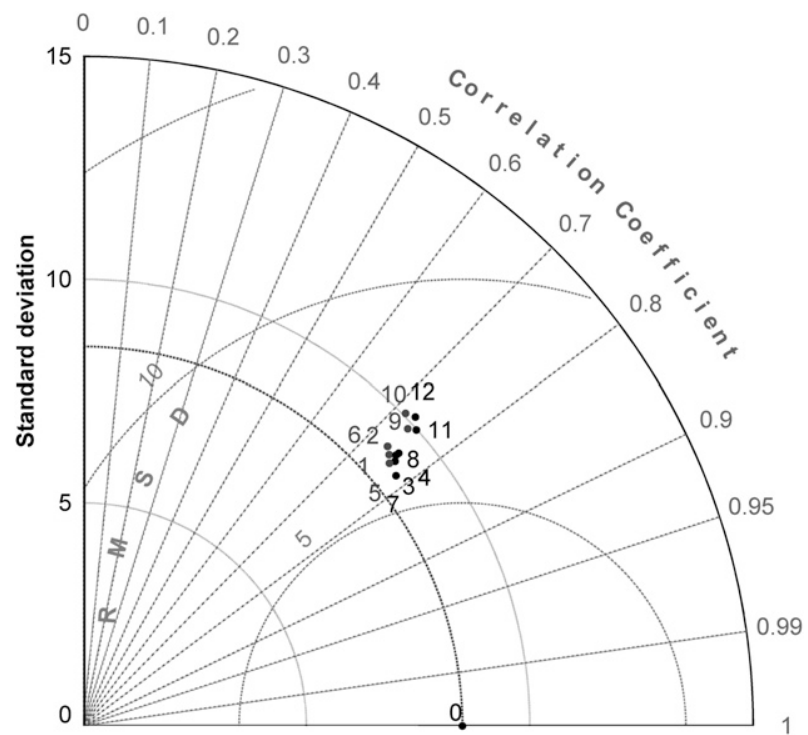

FIG. 17. Taylor diagram showing correlation coefficient, RMSD, and standard deviation of mean sea level pressure relative to E-OBS of the 12 simulations listed in Table 1 for the France subregion. that employ the MYNN3 PBL scheme show a greater degree of variability compared with the observations than those using the YSU scheme.

- Of the eight Rockel regions examined, WRF appears to be better at simulating the climate of regions 1 (British Isles) and 2 (Iberian Peninsula), while it is

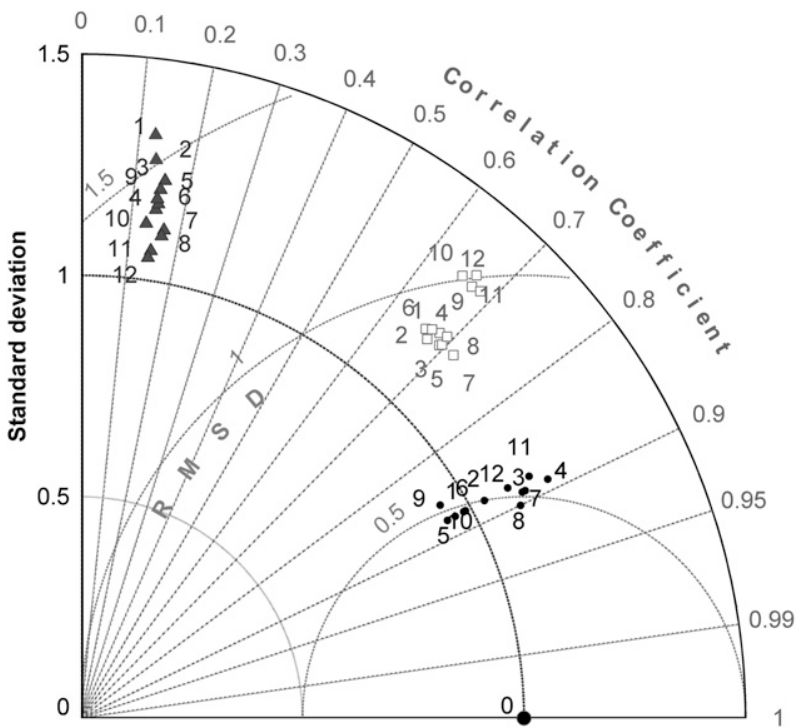

FIG. 18. Taylor diagram showing correlation coefficient, RMSD, and standard deviation of all three variables-surface air temperature (1-12 circle), daily mean precipitation (1-12 triangle), and mean sea level pressure (MSLP) (1-12 square) -relative to E-OBS of the 12 simulations listed in Table 1 for the mid-Europe subregion. To represent all three variables on this diagram, the standard deviation of each modeled variable has been normalized to the standard deviation of the observations. 


\section{(a) Simulation 6}
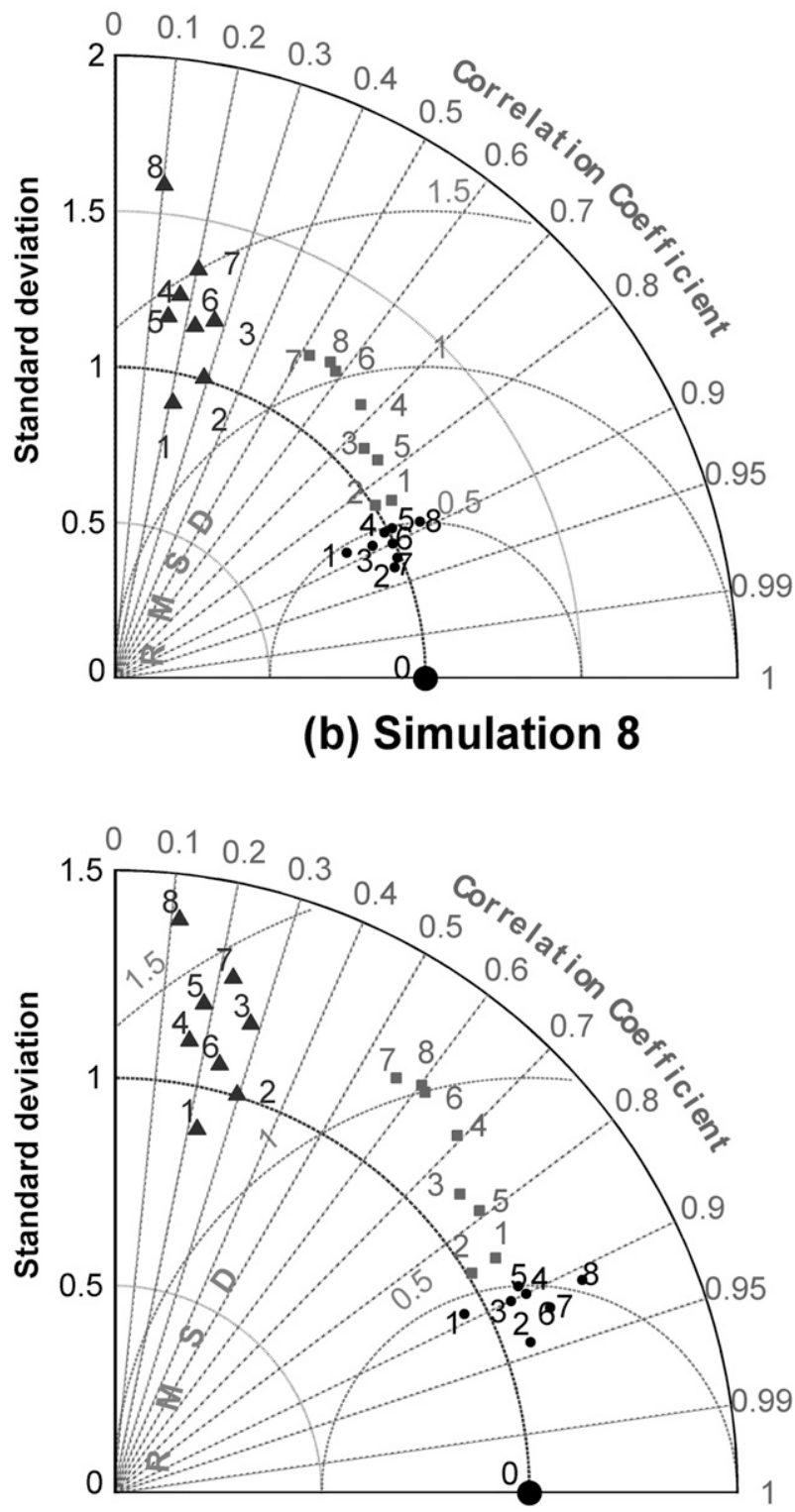

FIG. 19. (a). Taylor diagram showing correlation coefficient, RMSD, and standard deviation of all three variables [surface air temperature (1-8 circle) and daily mean precipitation (1-8 triangle) and mean sea level pressure (1-8 square)] relative to E-OBS for the eight subregions shown in Fig. 1 for simulation 6 only. (b). As in (a), but for simulation 8 only.

weakest in regions 7 (Mediterranean) and 8 (eastern Europe). Different combinations of the four parameterizations are seen to suit different Rockel regions, demonstrating the importance of undertaking thorough preliminary studies of WRF prior to any application.
Acknowledgments. P. A. Mooney acknowledges funding from the Irish Research Council for Science, Engineering and Technology, co-funded by Marie Curie Actions under FP7. This work is part funded under the Programme for Research in Third Level Institutions (PRTLI) administered by the Irish Higher Education Authority under the National Development Plan and with partial support from the European Regional Development Fund. A portion of this work was realized through access to NUI Maynooth's high-performance computing resources. ERA-Interim data used in this study have been obtained from the ECMWF data server: http://data.ecmwf.int/data. We acknowledge the E-OBS dataset from the EU-FP6 project ENSEMBLES (http:// www.ensembles-eu.org) and the data providers in the ECAD project (http://eca.knmi.nl). We thank two anonymous referees for constructive comments on an earlier version of the manuscript.

\section{REFERENCES}

Borge, R., V. Alexandrov, J. J. del Vas, J. Lumbreras, and R. Encarnación, 2008: A comprehensive sensitivity analysis of the WRF model for air quality applications over the Iberian Peninsula. Atmos. Environ., 42, 8560-8574.

Bukovsky, M. S., and D. J. Karoly, 2009: Precipitation simulations using WRF as a nested regional climate model. J. Appl. Meteor. Climatol., 48, 2152-2159.

Caldwell, P., H.-N. S. Chin, D. C. Bader, and B. Govindasamy, 2009: Evaluation of a WRF dynamical downscaling simulation over California. Climatic Change, 95, 499-521, doi:10.1007/ s10584-009-9583-5.

Christensen, J. H., and O. B. Christensen, 2007: A Summary of the PRUDENCE model projections of changes in European climate by the end of this century. Climatic Change, 81, 7-30, doi:10.1007/s10584-006-9210-7.

Collins, W. D., and Coauthors, 2004: Description of the NCAR Community Atmosphere Model (CAM3.0). NCAR Tech. Note TN-464+STR, 214 pp.

Dee, D. P., and Coauthors, 2011: The ERA-Interim reanalysis: Configuration and performance of the data assimilation system. Quart. J. Roy. Meteor. Soc., 137, 553-597, doi:10.1002/ qj.828.

Ek, M., and L. Mahrt, 1991: OSU 1-D PBL model user's guide, version 1.04. Department of Atmospheric Sciences, Oregon State University, $120 \mathrm{pp}$.

Evans, J. P., and M. F. McCabe, 2010: Regional climate simulation over Australia's Murray-Darling basin: A multi-temporal assessment. J. Geophys. Res., 115, D14114, doi:10.1029/2010JD013816.

Flaounas, E. S., S. Bastin, and S. Janicot, 2010: Regional climate modelling of the 2006 West African monsoon: sensitivity to convection and planetary boundary layer parameterisation using WRF. Climate Dyn., 36, 1083-1105, doi:10.1007/s00382010-0785-3.

Haylock, M. R., N. Hofstra, A. M. G. Klein Tank, E. J. Klok, P. D. Jones, and M. New, 2008: A European daily high-resolution gridded data set of surface temperature and precipitation for 1950-2006. J. Geophys. Res., 113, D20119, doi:10.1029/ 2008JD010201. 
Hong, S.-Y., J. Dudhia, and S.-H. Chen, 2004: A revised approach to ice microphysical processes for the bulk parameterization of clouds and precipitation. Mon. Wea. Rev., 132, 103-120.

—, Y. Noh, and J. Dudhia, 2006: A new vertical diffusion package with an explicit treatment of entrainment processes. Mon. Wea. Rev., 134, 2318-2341.

Jacob, D., and Coauthors, 2007: An inter-comparison of regional climate models for Europe: Model performance in presentday climate. Climatic Change, 81, 31-52, doi:10.1007/s10584006-9213-4.

Jankov, I., and Coauthors, 2011: An evaluation of five WRF-ARW microphysics schemes using synthetic GOES imagery for an atmospheric river event affecting the California coast. J. $\mathrm{Hy}$ drometeor., 12, 618-633.

Jin, J., N. L. Miller, and N. Schlegel, 2010: Sensitivity study of four land surface schemes in the WRF model. Adv. Meteor., 2010, 167436, doi:10.1155/2010/167436.

Kain, J. S., 2004: The Kain-Fritsch convective parameterization: An update. J. Appl. Meteor., 43, 170-181.

_ detraining plume model and its application in convective parameterization. J. Atmos. Sci., 47, 2784-2802.

Mellor, G. L., and T. Yamada, 1982: Development of a turbulence closure model for geophysical fluid problems. Rev. Geophys. Space Phys., 20, 851-875.

Mercader, J., B. Codina, A. Sairouni, and J. Cunillera, 2010: Results of the meteorological model WRF-ARW over Catalonia using different parameterizations of convection and cloud microphysics. Tethys, 7, 75-86.

Mitchell, T. D., and P. D. Jones, 2005: An improved method of constructing a database of monthly climate observations and associated high-resolution grids. Int. J. Climatol., 25, 693-712.

Mlawer, E. J., S. J. Taubman, P. D. Brown, M. J. Iacono, and S. A. Clough, 1997: Radiative transfer for inhomogeneous atmospheres: RRTM, a validated correlated- $k$ model for the longwave. J. Geophys. Res., 102, 16 663-16 682.

Molinari, J., and M. Dudek, 1992: Parameterization of convective precipitation in mesoscale numerical models: A critical review. Mon. Wea. Rev., 120, 326-344.

Mooney, P. A., F. J. Mulligan, and R. Fealy, 2011: Comparison of ERA-40, ERA-Interim and NCEP/NCAR reanalysis data with observed surface air temperatures over Ireland. Int. J. Climatol., 31, 545-557, doi:10.1002/joc.2098.

Morrison, H., G. Thompson, and V. Tatarskii, 2009: Impact of cloud microphysics on the development of trailing stratiform precipitation in a simulated squall line: Comparison of oneand two-moment schemes. Mon. Wea. Rev., 137, 991-1007.

Nakanishi, M., and H. Niino, 2004: An improved Mellor-Yamada level-3 model with condensation physics: Its design and verification. Bound.-Layer Meteor., 112, 1-31.

Perkins, S. E., A. J. Pitman, N. J. Holbrook, and J. McAneney, 2007: Evaluation of the AR4 climate models' simulated daily maximum temperature, minimum temperature, and precipitation over Australia using probability density functions. J. Climate, 20, 4356-4376.

Prabha, T. V., G. Hoogenboom, and T. G. Smirnova, 2011: Role of land surface parameterizations on modeling cold-pooling events and low-level jets. Atmos. Res., 99, 147-161.

Reichler, T., and J. Kim, 2008: How well do coupled models simulate today's climate? Bull. Amer. Meteor. Soc., 89, 303-311.

Salathé, E. P., Jr., L. R. Leung, Y. Qian, and Y. Zhang, 2010: Regional climate model projections for the State of Washington. Climatic Change, 102, 51-75, doi:10.1007/s10584-010-9849-y.

Screen, J. A., and I. Simmonds, 2010: Erroneous Arctic temperature trends in the ERA-40 reanalysis: A closer look. J. Climate, 24, 2620-2627.

Skamarock, W. C., and Coauthors, 2008: A description of the Advanced Research WRF version 3. NCAR Tech. Note NCAR/TN-475+STR, 113 pp.

Smirnova, T. G., J. M. Brown, and S. G. Benjamin, 1997: Performance of different soil model configurations in simulating ground surface temperature and surface fluxes. Mon. Wea. Rev., 125, 1870-1884.

,,-- , and D. Kim, 2000: Parameterization of coldseason processes in the MAPS land surface scheme. J. Geophys. Res., 105, 4077-4086.

Solomon, S., D. Qin, M. Manning, Z. Chen, M. Marquis, K. B. Averyt, M. Tignor, and H. L. Miller, Eds., 2007: Climate Change 2007: The Physical Science Basis. Cambridge University Press, $996 \mathrm{pp}$.

Taylor, K. E., 2001: Summarizing multiple aspects of model performance in a single diagram. J. Geophys. Res., 106, 71837192.

Troy, T. J., and E. F. Wood, 2009: Comparison and validation of gridded radiation products across northern Eurasia. Environ. Res. Lett., 4, 045008, doi:10.1088/1748-9326/4/4/045008.

van den Besselaar, E. J. M., M. R. Haylock, G. van der Schrier, and A. M. G. Klein Tank, 2011: A European daily highresolution observational gridded data set of sea level pressure. J. Geophys. Res., 116, D11110, doi:10.1029/2010JD015468.

Wang, W., and N. L. Seaman, 1997: A comparison study of convective parameterization schemes in a mesoscale model. Mon. Wea. Rev., 125, 252-278.

Yu, E.-T., H.-J. Wang, and J.-Q. Sun, 2010: A quick report on a dynamical downscaling simulation over China using the nested model. Atmos. Oceanic Sci. Lett., 3, 325-329.

Zhang, D.-L., J. S. Kain, J. M. Fritsch, and K. Gao, 1994: Comments on "Parameterization of convective precipitation in mesoscale numerical models: A critical review." Mon. Wea. Rev., 122, 2222-2231.

Zhang, Y., V. Duliere, P. W. Mote, and E. P. Salathé, 2009: Evaluation of WRF and HadRM mesoscale climate simulations over the U.S. Pacific Northwest. J. Climate, 22, 55115526 . 
Copyright of Journal of Climate is the property of American Meteorological Society and its content may not be copied or emailed to multiple sites or posted to a listserv without the copyright holder's express written permission. However, users may print, download, or email articles for individual use. 